\title{
Bleeding Meckel's diverticulum in a 4-month-old infant: Treatment with laparoscopic diverticulectomy. A case report and review of the literature
}

\author{
J Rainer Poley' \\ Thomas E Thielen ${ }^{2}$ \\ Jeffrey C Pence ${ }^{3}$ \\ 'Clinical Professor of Pediatrics, \\ Section of Pediatric Gastroenterology, \\ Hepatology and Nutrition; ${ }^{2}$ Resident \\ in Pediatrics; ${ }^{3}$ Assistant Professor \\ of Surgery and Pediatrics, Section \\ of Pediatric Surgery, Brody \\ School of Medicine, East Carolina \\ University, Greenville, NC, USA
}

\begin{abstract}
A bleeding Meckel's diverticulum is presented in a 4-month-old African American infant. This event is rare at this age, and our patient is only the second 4-month-old infant reported in the English literature. The infant presented with painless frank rectal bleeding, the blood being maroon-colored, and clots were found in the diaper. There was also anemia, with an hemoglobin of less than $8 \mathrm{gm} / \mathrm{dl}$. The color of the blood suggested a bleeding site in the ileocecal region, a Meckel's diverticulum was suspected, which was then confirmed by an isotope scan. A typical Meckel's diverticulum was found on laparoscopic surgery, was excised, and the infant made an uneventful recovery.
\end{abstract}

Keywords: infant-bleeding Meckel's diverticulum, laparoscopic diverticulectomy

\section{Case report}

A 4-month-old African American male infant (MC) was admitted to Children's Hospital of East Carolina because of rectal bleeding and anemia. The infant had been in good general health until the day of admission when, in the morning of the same day, he had a rather marked episode of painless frank rectal bleeding without any recognizable preceding event. The blood in the diaper was maroon-colored, and there were clots. There was no history of ano-rectal trauma or previous rectal bleeding. No fever, diarrhea, or vomiting were reported. Feedings consisted of Enfamil Lipil, which he always took well. Growth and weight gain as well as psychomotor development were normal. Past medical history was remarkable only for transient gastroesophageal reflux, which had become asymptomatic. Family history was noncontributory.

On physical examination, the infant appeared well-nourished, alert, and in no acute distress. Weight was $6.64 \mathrm{~kg}$, respiration rate $28 / \mathrm{min}$, blood pressure $93 / 50$, heart rate $132 \mathrm{bpm}$. He had a 1-2/6 systolic murmur (anemia). Abdomen was soft and nontender, with a small umbilical hernia; there was no hepato-splenomegaly, and no masses were palpable. Rectal exam showed hemoccult-positive material on the examining glove. Laboratory data: WBC 10.3, hemoglobin $7.7 \mathrm{gm} / \mathrm{dl}$, hematocrit $22 \%$, platelet count was $645 \mathrm{~K}$; serum electrolytes, liver panel, prothrombin, and partial thromboplastin times were all normal.

Because of a suspected bleeding Meckel's diverticulum (MD), a radionuclide scan with $99 \mathrm{~m}$ Tc-pertechnetate was performed (after pre-treatment with an $\mathrm{H} 2$ receptor antagonist [Cimetidine; GlaxoSmithKline]), which showed a "blush" or increased radiotracer uptake in the mid-lower abdomen, which was highly suggestive of an MD.

Subsequently, a laparoscopy-assisted diverticulectomy was done one day after admission. During the operative procedure, no obstructive features were seen, but the tip of the diverticulum was attached to a fibrous band, which inserted into the root of the mesentery. This band was transected, allowing free mobility of the diverticulum, 
which was removed by simple excision. Height of the diverticulum was measured at $28-30 \mathrm{~mm}$, the base was $15 \mathrm{~mm}$, giving a height:diameter ratio of about 2 . The tip of the diverticulum appeared thickened. After resection and inspection, a contracted ulceration was identified in the area of ectopic gastric tissue at the junction to the thickened mucosa, which was shown to harbor ectopic pancreatic tissue. During the same session, the umbilical hernia was repaired. No other intra-abdominal abnormalities were encountered, as have been mentioned by St. Vil and colleagues. ${ }^{1}$ The infant made an uneventful recovery, and on follow-up examination (JCP), all appeared to be well.

Pathological examination of the excised diverticulum showed ectopic gastric mucosa of the parietal cell variety, as well as ectopic pancreatic tissue.

\section{Discussion}

\section{Frequency and clinical presentations of a MD in infants}

$\mathrm{MD}$ is the most common congenital abnormality of the intestinal tract, and it represents the nonobliterated remnant of the omphalo-mesenteric or vitelline duct. Its tip can sometimes be attached to the mesenteric root $(25 \%$ and as in the case on record), by the fibrous remnant of one of the vitelline arteries. $^{2}$

We were able to find only one other infant (boy) aged four months with a bleeding MD in the accessible English literature. ${ }^{3}$ However, according to a report by Vane and colleagues, ${ }^{4}$ the age range of 48 patients with a bleeding MD was four months to four years, but no further age details were given. Imaeda and colleagues ${ }^{5}$ reported a 7-month-old boy with an intermittently bleeding MD. In a review of 158 infants less than one year old with intestinal bleeding (no further age details), only six (3.8\%) presented with a bleeding MD. ${ }^{6}$

Brookes ${ }^{7}$ reported on 43 children with $\mathrm{MD}$, and the youngest patient with a bleeding MD was nine months old. Rutherford and Akers ${ }^{8}$ showed that 43 of 80 patients with symptomatic presentation had a bleeding MD, and $60 \%$ of their patients presented with that symptom, but no age range was available. In a 20-year review by St. Vil and colleagues ${ }^{1}$ from the Hôpital St. Justine (Montréal PQ), bleeding occurred in 45 of 164 (27\%) of patients with an MD, and 60\% were less than five years old, but no other age indicators were presented.

In a review from Spain ${ }^{9}$ of 18 patients with an MD, the youngest one was five months old, but no further details are known.
Pellerin and colleagues ${ }^{10}$ presented 250 pediatric patients from France, of which 30\% had an MD with hemorrhage, and only five of 35 patients were less than seven years old. Unfortunately, no other details are known.

The expanded rule of 2's is usually clinically applicable:

1. Occurs in about $2 \%$ of the population ( $1 \%$ in one series, ${ }^{11}$ $3 \%$ in another ${ }^{12}$ )

2. Located in the distal ileum, within two feet of the ileocecal valve

3. Usually two inches in length

4. Commonly $2 \mathrm{~cm}$ in diameter

5. 2:1 male:female ratio

6. Two ectopic tissues (gastric and pancreatic)

7. Commonly symptomatic before two years old

Symptomatic MD due to hemorrhage is said to be quite rare in the neonatal period. ${ }^{2,13}$ The cause of bleeding from an MD is usually due to ulceration either in the ectopic gastric tissue within the diverticulum, or due to ulceration (acid-related), in the ileal mucosa adjacent to the diverticulum. ${ }^{14,15}$ Bleeding per rectum is usually painless, the color of the blood can be either be bright red, probably due to brisk bleeding and more rapid colonic transit, but more often it is maroon-colored and may be associated with clots, whereas a tarry stool is infrequent, ${ }^{8}$ presumably due to a slow rate of bleeding and decreased colonic transit.

Bleeding may be episodic, and sometimes can be massive, leading to a significant decrease in hemoglobin, usually $<8 \mathrm{gm} / \mathrm{dl}$ (Poley, pers comm). ${ }^{8}$

Complications, other than hemorrhage due to an MD in the newborn period are more common, such as peritonitis due to perforation, obstruction due to volvulus because of omphalomesenteric or meso-diverticular bands. ${ }^{4,8,14}$

\section{Pathology}

An MD is located on the antimesenteric side of the distal ileum, it may be situated anywhere between $20 \mathrm{~cm}^{2}$ to $90 \mathrm{~cm}$ proximal to the ileo-ceal valve. ${ }^{16}$ The length of an MD is usually $2-3 \mathrm{~cm}$, although giant forms have been described. ${ }^{16}$ Ectopic or heterotopic tissues from other sites of the gastrointestinal tract may be present in a symptomatic MD (Table 1). Heterotopic tissue, which was mostly gastric, occurred in all patients presenting with intestinal hemorrhage. Langerhans islets were identified in pancreatic heterotopic tissue. ${ }^{9}$

Whereas gastric heterotopic tissue is responsible for bleeding in an $\mathrm{MD}$, presence of pancreatic tissue, owing to ist mass effect, may act as a leading point for intussusception and volvulus. ${ }^{1}$ 
Table I Heterotopic tissue in symptomatic Meckel's diverticulum (in infants and children)

\begin{tabular}{lllll}
\hline Authors & \% Gastric & \% Pancreatic & \% Gastric and pancreatic & Other (uncommon) \\
\hline Rutherford and Akers $^{8}$ & 97 & NA & NA & Jejunal duodenal \\
Pellerin and colleagues $^{10}$ & 79 & 3 & NA & Colonic (mentioned) \\
Artigas and colleagues $^{9}$ & 62 & 15 & 23 & \\
Kusumoto and colleagues $^{14}$ & $80-100$ & 6 & NA & Gastric and colonic \\
St. Vil and colleagues' & 88 & 7 & 3 & \\
Vane and colleagues $^{4}$ & 90 & $5-16$ & 5 & NA \\
Snyder & 78 & 5 & NA & Colonic \\
Park and colleagues & & 5 & &
\end{tabular}

Abbreviation: NA, not available.

\section{Diagnostic approach}

The now most commonly used diagnostic modality is the scintiscan (Meckel's scan) employing $99 \mathrm{~m}$ Technetium Pertechnetate, which is preferentially taken up by the mucus/ acid secreting cells of the gastric mucosa. ${ }^{17} \mathrm{~A} 10$-year review of 954 scintiscans (mixed population) for the diagnosis of an MD found that only $1.7 \%$ were false-negative, and $0.05 \%$ were false-positive, giving a sensitivity of $85 \%$, and a specificity of $95 \%$, with an accuracy of $90 \% .{ }^{15}$ These scans are said to have a greater diagnostic accuracy in children with a sensitivity of $95 \%,{ }^{18}$ as compared to adults. Swaniker and colleagues ${ }^{19}$ showed that the negative predictive value of the scinitiscan was $74 \%$ in pediatric patients with a hemoglobin of $<11 \mathrm{gm} / \mathrm{dl}$, ( 8 of 31 patients with a bleeding MD). The same authors feel, that in such situation, the scintiscan would limit the contribution of the test in clinical decision making.

Efforts have been made, to enhance the accuracy of the Meckel's scan. Sfakianakis and colleagues ${ }^{20}$ have tested the usefulness of Meckel's scan on experimental MDs fashioned in dogs, and found that pentagastrin, compared with other gastrointestinal hormones, enhanced the uptake of the radionuclide by the ectopic gastric mucosa. However, increased acid secretion stimulated by pentagastrin in gastric tissue may be clinically undesirable. ${ }^{21}$

The H2-receptor antagonist cimetidine (GlaxoSmithKline) has also been used to enhance the accuracy of the scintiscan for the detection of an MD. ${ }^{21,22}$ Cimetidine is thought to prevent the release of pertechnetate from the gastric cells, allowing the possible conversion of a negative to a positive scan. We believe that, in our patient with a hemoglobin much lower then $11 \%$, pre-treatment with cimetidine contributed to the positive result of the scintiscan. Sfakianakis and colleague $^{23}$ have already shown that cimetidine increased the sensitivity of the scintiscan to $>90 \%$, that the drug is safe with no significant risk of side effects.
Ultrasonography has been used as a diagnostic means to detect an $\mathrm{MD},{ }^{24,25}$ as the visualization of a tubular hyperechoic structure could be suggestive of an MD. Also, routine color Doppler sonography may show anomalous vessels as well as inflammation on the wall of the diverticulum. Barium contrast studies of the gastrointestinal tract and arteriography have a low diagnostic yield. ${ }^{14}$

\section{Treatment}

The treatment of choice of a bleeding or another complication causing MD is diverticulectomy. This has been done through exploratory laparotomy, but with the advent of laparoscopic techniques, such approach has become feasible in infants and small children. ${ }^{24-26}$ In the two latter reports, the youngest patient was seven months old. Thus, we think that the laparoscopic resection of the MD in our patient could have been a surgical first, but it could conceivably have been done before and been unpublished. At any rate, this technique is feasible by an experienced surgeon, even in young infants.

In summary, a high degree of suspicion should prevail for an MD in an infant even at a very young age, who presents with painless rectal bleeding (very often maroon-colored with clots), without preceding intestinal symptoms, and with a hemoglobin of $<8 \mathrm{gm} / \mathrm{dl}$.

\section{Acknowledgments}

The authors gratefully acknowledge the assistance of Ms Joelle Holland, and Ms Anna Penny in the preparation of this manuscript.

\section{Disclosure}

The authors report no conflicts of interest in this work.

\section{References}

1. St. Vil D, Brandt ML, Panic S, Bensoussan AL, Blanchard H. Meckel's diverticulum in children: a 20-year review. J Ped Surg. 1991;26:1289-1292.

2. Irving IM. Umbilical abnormalities. In: Lister J, Irving IM, editors. Neonatal Surgery. London, UK: Butterworths and Co; 1990. p. 397. 
3. Dutro JA, Santanello SA, Unger F, Goodwin CD. Rectal bleeding in a 4 months old boy. JAMA. 1986;256:2239-2240.

4. Vane DW, West KW, Grosfeld JL. Vitelline duct anomalies. Experience with 217 childhood cases. Arch Surg. 1987;122:542-547.

5. Imaeda $T$, Kanematsu M, Sone $Y$, et al. A case of intermittent bleeding Meckel's diverticulum. Ann Nucl Med. 1990;4:107-110.

6. Berman WF, Holtzapple PG. Gastro-intestinal hemorrhage. Pediatr Clin NA. 1975;23:885-895.

7. Brookes VS. Meckel's diverticulum in children. A report of 43 cases. Br J Surg. 1954;42:57-68.

8. Rutherford RB, Akers DR. Meckel's diverticulum: a review of 148 pediatric patients with special reference to the pattern of bleeding, and to meso-diverticular bands. Surgery. 1966;59:618-628.

9. Artigas V, Calabuig R, Badia F. Meckel's diverticulum: value of ectopic tissue. Am J Surg. 1986;151:631-634.

10. Pellerin D, Harouchi A, Delmas P. Le diverticule de Meckel, revue de 250 cas chez l'enfant. Ann Chir Infant. 1976;17:157-172.

11. Brown RL, Azizkhan RG. Gastro-intestinal bleeding in infants and children: Meckel's diverticulum and intestinal duplication. Semin Pediatr Surg. 1999;8:202-209.

12. Park JJ, Wolff BG, Tollefson MK, et al. Meckel diverticulum. The Mayo Clinic experience with 1476 patients (1950-2002). Ann Surg. 2005;241:529-533.

13. Lloyd DA. Omphalomesenteric duct remnants. In: Puri P, editor. Newborn Surgery. London, UK: Arnold; 2003. p. 615-617.

14. Kusumoto H, Yoshida M, Takahashi I, Anai H, Maehara Y, Sugimachi K. Complications and diagnosis of Meckel's diverticulum in 776 patients. Am J Surg. 1992;164:382-383.

15. Snyder CL. Meckel's diverticulum. In: Grosfeld JL, O'Neill JA, Coran AG, Fonkalsrud EW, editors. Pediatric Surgery. Philadelphia, PA: Mosby/Elsevier; 2003. p. 1304-1312.

16. Moses WR. Meckel's diverticulum, a report of two unusual cases. N Engl J Med. 1947;237:118-122.
17. Diamond RH, Rothstein RD, Alavi A. The role of cimetidine-enhanced technetium-99m-pertechnetate imaging for visualizing Meckel's diverticulum. J Nucl Med. 1991;32:1422-1424.

18. Vinton NE. Gastrointestinal bleeding in infancy and childhood. Gastroenterol Clin NA. 1994;23:93-121.

19. Swaniker F, Soldes O, Hirschi RB. The utility of technetium $99 \mathrm{~m}$ Pertechnetate scintigraphy in the evaluation of patients with Meckel's diverticulum. J Ped Surg. 1999;34:760-765.

20. Sfakianakis GN, Anderson GF, King DR, Boles ET. The effect of gastrointestinal hormones on the pertechnetate imaging of ectopic gastric mucosa in experimental Meckel's diverticulum. J Nucl Med. 1981;22:678-683.

21. Diamond RH, Rothstein RD, Alavi A. The role of cimetidine-enhanced technetium $99 \mathrm{~m}$ Pertechnetate imaging for visualizing Meckel's diverticulum. J Nucl Med. 1991;32:1422-1424.

22. Petrokubi RJ, Baum S, Rohrer GV. Cimetidine administration resulting in improved Pertechnetate imaging of Meckel's diverticulum. Clin Nucl Med. 1978;3:385-388.

23. Sfakianakis GN, Conway JJ. Detection of ectopic gastric mucosa in Meckel's diverticulum and in other aberrations by scintigraphy; II. Indications and methods. A 10 year experience. J Nucl Med. 1981; 22:732-738.

24. Panuel M, Campan N, Delarue A, Petit P, Sarles J, Devred P. Ultrasonographic diagnosis and laparoscopic surgical treatment of Meckel's diverticulum. Eur J Pediatr Surg. 1994;4:344-345.

25. Baldiserotto M, Maffazzoni DR, Dora MD. Sonographic findings of Meckel's diverticulitis in children. AJR Am J Roentgenol. 2003;180:425-428.

26. Clark JM, Koontz JS, Smith LA, Kelley JE. Video-assisted transumbilical diverticulectomy in children. Am Surg. 2008;74:327-329.

27. Chan KW, Lee KH, Mou JW, Cheung ST, Tam YH. Laparoscopic management of complicated Meckel's diverticulum in children: a 10- year review. Surg Endosc. 2008;22:1509-1512. 